\title{
Papers
}

\section{Twice daily versus four times daily insulin dose regimens for diabetes in pregnancy: randomised controlled trial}

\author{
Zohar Nachum, Izhar Ben-Shlomo, Ehud Weiner, Eliezer Shalev
}

\begin{abstract}
Objective To compare perinatal outcome and glycaemic control in two groups of pregnant diabetic patients receiving two insulin regimens. Design Randomised controlled open label study. Setting University affiliated hospital, Israel. Participants 138 patients with gestational diabetes mellitus and 58 patients with pregestational diabetes mellitus received insulin four times daily, and 136 patients with gestational diabetes and 60 patients with pregestational diabetes received insulin twice daily. Intervention Three doses of regular insulin before meals and an intermediate insulin dose before bedtime (four times daily regimen), and a combination of regular and intermediate insulin in the morning and evening (twice daily regimen).

Main outcome measures Maternal glycaemic control and perinatal outcome.

Results Mean daily insulin concentration before birth was higher in the women receiving insulin four times daily compared with twice daily: by 22 units $(95 \%$ confidence interval 12 to 32) in patients with gestational diabetes and by 28 units ( 15 to 41 ) in patients with pregestational diabetes. Glycaemic control was better with the four times daily regimen than with the twice daily regimen: in patients with gestational diabetes mean blood glucose concentrations decreased by $0.19 \mathrm{mmol} / \mathrm{l}(0.13$ to 0.25$), \mathrm{HbA}_{1 \mathrm{c}}$ by $0.3 \%(0.2 \%$ to $0.4 \%$ ), and fructosamine by $41 \mu \mathrm{mol} / \mathrm{l}$ (37 to 45 ), and adequate glycaemic control (mean blood glucose concentration $<5.8 \mathrm{mmol} / \mathrm{l})$ was achieved in $17 \%(8 \%$ to $26 \%$ ) more women; in patients with pregestational diabetes mean blood glucose concentration decreased by $0.44 \mathrm{mmol} / \mathrm{l}(0.28$ to 0.60$), \mathrm{HbA}_{1 \mathrm{c}}$ by $0.5 \%(0.2 \%$ to $0.8 \%$ ), and fructosamine by $51 \mu \mathrm{mol} / \mathrm{l}$ (45 to 57 ), and adequate glycaemic control was achieved in 31\% (15\% to $47 \%$ ) more women. Maternal severe hypoglycaemic events, caesarean section, preterm birth, macrosomia, and low Apgar scores were similar in both dose groups. In women with gestational diabetes the four times daily regimen resulted in a lower rate of overall neonatal morbidity than the twice daily regimen (relative risk $0.59,0.38$ to 0.92 ), and the relative risk for hyperbilirubinaemia and hypoglycaemia was lower ( $0.51,0.29$ to 0.91 and $0.12,0.02$ to 0.97 respectively). The relative risk of hypoglycaemia in newborn infants to mothers with pregestational diabetes was 0.17 ( 0.04 to 0.74 ).
\end{abstract}

Conclusions Giving insulin four times rather than twice daily in pregnancy improved glycaemic control and perinatal outcome without further risking the mother.

\section{Introduction}

Diabetes mellitus complicates around 5\% of pregnancies. Good glycaemic control, aimed at reducing both maternal and perinatal morbidity, is the cornerstone of treatment. ${ }^{1-5}$ Several aspects of glycaemic control have been addressed, such as time and standards of diagnosis, ${ }^{5-7}$ the appropriate time and glucose concentrations at which to begin insulin treatment, ${ }^{258}$ and the tightness of control..$^{24}$ It is now widely accepted that measures to achieve glycaemic control should be initiated before conception in pregestational diabetes and as early as diagnosis in gestational diabetes. ${ }^{5}$

Patients with pregestational diabetes are strictly managed with insulin before conception or when first enrolled for antenatal surveillance, whereas patients with gestational diabetes receive insulin once dietary control proves ineffective. ${ }^{5}$ The diabetes control and complications trial in non-pregnant women found that intensification of insulin administration achieved "normoglycaemia" and reduced the rate of long term complications..$^{10}$ The most widely used regimen for patients with pregestational or gestational diabetes is insulin twice daily, ${ }^{11}$ the morning dose containing two thirds of the total daily insulin and the afternoon dose containing one third of the total daily insulin. The morning dose comprises one third regular short acting insulin and two thirds intermediate insulin whereas the evening dose comprises equal amounts of regular and intermediate insulin. The disadvantages of this regimen are relative fasting and hyperglycaemia after lunch and possible nocturnal hypoglycaemia, which have negative effects on fetal and maternal wellbeing. ${ }^{12}$ The Diabetes Control and Complications Trial Group compared an intensive four times daily regimen of insulin ${ }^{13}$ with a twice daily regimen in nonpregnant women but applied only the intensified version to those who planned pregnancy or had conceived. $^{14}$ During pregnancy no prospective randomised comparison was made between the two regimens to test possible implications for perinatal outcome. We compared glycaemic control, maternal complications, and perinatal outcome between two groups each containing 196 pregnant women, treated

\author{
Department of \\ Obstetrics and \\ Gynecology, \\ HaEmek Medical \\ Center, Afula, Israel \\ Zohar Nachum \\ consultant \\ Izhar Ben-Shlomo \\ consultant \\ Eliezer Shalev \\ chairman \\ Ultrasound Unit, \\ HaEmek Medical \\ Center \\ Ehud Weiner \\ director \\ Correspondence to: \\ E Shalev \\ shaleve@netvision. \\ net.il
}

BMJ 1999;319:1223-7

website

extra

The flow of participants through the trial appears on the $B M J$ 's website

www.bmj.com 
with either twice daily or four times daily insulin dose regimens (see website).

\section{Participants and methods}

Assignment

From 1 January 1993 to 31 December 1997 we enrolled patients with pregestational diabetes and gestational diabetes who required insulin treatment. Patients gave their informed consent. HaEmek Medical Center is the central referral hospital for a population of 400000 for whom the clinic is the only one specialising in gestational diabetes. We included only singleton pregnancies in which insulin treatment was began before 35 weeks' gestation. We diagnosed gestational diabetes according to the criteria of the National Diabetes Data Group: 100 g oral glucose ingestion followed by at least two serum glucose concentration values equal to or above 5.9, 10.6, 9.2, 8.1 $\mathrm{mmol} / \mathrm{l}$ at $0,1,2$, and 3 hours respectively. ${ }^{6}$

\section{Protocols}

\section{Insulin administration}

Twice daily regimen-The morning dose contained two thirds of the total daily insulin and the afternoon dose contained one third of the total daily insulin. The morning dose comprised one third human regular insulin (Actrapid, NovoNordisk, Denmark) and two thirds human intermediate insulin (Insulatard, NovoNordisk), and the evening dose comprised equal amounts of regular and intermediate insulin. According to patients' response adjustments were individualised for the amount of total insulin and the ratio between the insulins.

Four times daily regimen-The first three doses of regular insulin were given by insulin pen (Novopen 3, NovoNordisk) half an hour before each main meal, and the fourth dose of intermediate insulin was given before bedtime.

\section{Glycaemic control}

The dietary recommendations were $0.13-0.15 \mathrm{MJ} / \mathrm{kg}$ ideal body weight, given as three meals and three snacks daily and composed of 55\% carbohydrate, $20 \%$ protein, and $25 \%$ fat, with increased complex and decreased refined carbohydrates. ${ }^{58}$ Control was assessed by glucose monitoring and by monthly measurements of glycated haemoglobin $\mathrm{A}_{1 \mathrm{c}}$ and fructosamine. Capillary whole blood glucose was measured by the glucose kinase method when women were admitted to hospital and by self monitoring glucose reflectance meters at home (Accutrend, Boehringer Ingelheim, Germany); values were verified by the glucometer's memory. Seven measurements were taken daily until adequate control was achieved, and thereafter measurements were taken at least twice weekly. We made telephone contact with patients at home as needed. Goals for glycaemic control were blood glucose concentrations of 3.3-5.3 mmol/1 before meals, $6.7 \mathrm{mmol} / \mathrm{l}$ or less 2 hours after meals, and mean daily values of $4.4-5.3 \mathrm{mmol} / \mathrm{l}$. The upper values served as the threshold for initiation of insulin or increase of dose thereafter. We aimed for $\mathrm{HbA}_{1 \mathrm{c}}$ concentrations below $6.0 \%$ (measured in whole blood by agar gel electrophoresis; Titan Gel Multi-Slot
Glyco-17, Helena Laboratories, USA; normal values 3.7\%-6.0\%). Severe maternal hypoglycaemia was defined as a state severe enough to prevent the patient from independently taking oral glucose and requiring help from another person.

\section{Follow up}

In most cases gestational age was confirmed by fetal crown-rump length, measured during the first trimester. Thereafter patients were followed according to the guidelines set by the American College of Obstetricians and Gynecologists.

\section{Labour and delivery}

An important objective of our protocol was for infants to be delivered at term. The timing of induction of labour was determined by an overall assessment of maternal and fetal risk factors including poor compliance, suboptimal glycaemic control, vasculopathy, macrosomia, suspicious fetal biophysical test, and poor obstetrical history. Patients with both an uncomplicated gestational diabetes and an unfavourable cervix were allowed to await spontaneous onset of labour. Delivery was induced if there was a favourable cervix at 38-41 weeks' gestation or if the patient had not delivered by 41 weeks. Treatment was individualised for those women with gestational diabetes whose pregnancy was complicated. Timing of delivery in women with pregestational diabetes was also on the basis of the overall obstetric, medical, and metabolic assessment of the pregnancy, as well as cervical assessment. Amniocentesis for fetal pulmonary maturity was performed in women to be delivered before 38 weeks' gestation. We aimed for glucose concentrations of 3.3$5.6 \mathrm{mmol} / \mathrm{l}$ during labour and delivery.

\section{Neonatal care}

At delivery the neonate was attended by the neonatal staff. Blood samples were taken six times during the first day of life for measurement of plasma glucose concentrations. Haematocrit and calcium concentrations were measured immediately after birth and thereafter if indicated. Bilirubin was measured 1-3 times from the first day of life as indicated.

\section{Randomisation and data analysis}

Randomisation was on the basis of a computer generated list of numbers, sealed in numbered opaque envelopes, which were opened sequentially. We analysed data with $t$ test, $\chi^{2}$ test, Fisher's exact test, and non-parametric tests as applicable. From past analysis our data indicated that neonatal morbidity was about $30 \%$ in gestational diabetes and about $50 \%$ in pregestational diabetes. Diagnoses included in the definition of neonatal morbidity were: hyaline membrane disease, hypoglycaemia, hypocalcaemia, hyperbilirubinaemia, and birth trauma. Our calculations before initiating the study showed that to detect a reduction to $15 \%$ and $25 \%$ at least 119 patients with gestational diabetes and 56 patients with pregestational diabetes respectively would be needed in each arm for an $\alpha$ type error of 0.05 and power of 0.8 , for a two tailed consideration. $\mathrm{P}$ values of $<0.05$ were considered significant. 


\section{Results}

We studied 274 patients with gestational diabetes and 118 patients with pregestational diabetes; 136 women with gestational diabetes and 60 women with pregestational diabetes received the twice daily regimen and 138 and 58 women respectively received the four times daily regimen. There were no significant differences in the case mix of the groups and in the frequency of background factors known to be associated with adverse outcome of pregnancy (table 1). In patients with gestational diabetes there was no differences in the time of diagnosis and the time when insulin treatment was started between the two dose regimens. In patients with pregestational diabetes, treatment was started in the same week for both regimen groups. Overall glycaemic control, as reflected in mean daily concentrations of glucose, $\mathrm{HbA}_{1}$, and fructosamine, was significantly better with the four times daily regimen than with the twice daily regimen (table 2 ). This was consequent on higher mean dose of insulin given to the patients who received insulin four times daily compared with twice daily but importantly without an increase in episodes of severe maternal hypoglycaemia. No difference was found between all subgroups for gestational week at delivery and rates of both caesarean section and pregnancy induced hypertension. Table 3 summarises the perinatal and neonatal outcome data. Whereas perinatal mortality was similar in both regimen groups the rate of overall morbidity was lower in the four times daily than twice daily regimen. This was significant in the group with gestational diabetes (relative risk 0.59, 95\% confidence interval 0.38 to 0.92 ) but not in the group with pregestational diabetes. In neonates born to mothers with gestational diabetes the most prevalent complications of hypoglycaemia and hyperbilirubinaemia were lower in those whose mothers received the four times daily regimen compared with twice daily regimen. Relative risks for hypoglycaemia and hyperbilirubinaemia were 0.12 (0.02 to 0.97$)$ and 0.51 (0.29 to 0.91$)$ for the four times daily and twice daily regimen groups respectively. In the pregestational diabetes groups only the difference in the rate of neonatal hypoglycaemia was significant: relative risks for the four times daily compared with twice daily regimen was 0.17 (0.04 to 0.74$)$.
Table 1 Characteristics of pregnant diabetic women. Values are means (SD) unless stated otherwise

\begin{tabular}{|c|c|c|c|c|}
\hline \multirow[b]{2}{*}{ Characteristic } & \multicolumn{2}{|c|}{ Gestational diabetes } & \multicolumn{2}{|c|}{ Pregestational diabetes } \\
\hline & $\begin{array}{l}\text { Insulin } \\
\text { twice daily }\end{array}$ & $\begin{array}{l}\text { Insulin four } \\
\text { times daily }\end{array}$ & $\begin{array}{l}\text { Insulin } \\
\text { twice daily }\end{array}$ & $\begin{array}{l}\text { Insulin four } \\
\text { times daily }\end{array}$ \\
\hline No of women & 136 & 138 & 60 & 58 \\
\hline Age & $33(5)$ & $33(5)$ & $31(6)$ & $32(6)$ \\
\hline Jewish/non-Jewish & $75 / 61$ & $78 / 60$ & $33 / 27$ & $33 / 25$ \\
\hline Gravidity & $3.4(1.8)$ & $3.5(1.7)$ & $3.5(2.8)$ & $3.6(2.5)$ \\
\hline Prepregnancy weight $(\mathrm{kg})$ & $72(15)$ & $73(15)$ & $70(16)$ & $71(17)$ \\
\hline Body mass index & $27.8(2.7)$ & $27.9(2.6)$ & $27.0(3.1)$ & $27.1(3.0)$ \\
\hline Gestational week at diagnosis & $26.3(7.2)$ & $25.9(7.1)$ & - & - \\
\hline $\begin{array}{l}\text { Gestational week at start of } \\
\text { treatment }\end{array}$ & $28.0(6.9)$ & $27.4(6.8)$ & $12.9(7.0)$ & $12.4(6.2)$ \\
\hline No with type 1/type 2 diabetes & - & - & $31 / 29$ & $30 / 28$ \\
\hline No (\%) with vasculopathy* & - & - & $12(20)$ & $13(22)$ \\
\hline
\end{tabular}

${ }^{*}$ Class $\mathrm{D}$ (benign retinopathy), $\mathrm{R}$ (proliferative retinopathy), and $\mathrm{F}$ (nephropathy) according to White's classification. ${ }^{15}$

\section{Discussion}

\section{Pathophysiology}

In 1967 Pedersen postulated that the attributes of infants born to diabetic mothers was due to intrauterine hyperinsulinism as a result of maternal hyperglycaemia. $^{17}$ The main features of fetal and neonatal conditions in these circumstances are increased rates of perinatal death, macrosomia, early hypoglycaemia, respiratory distress syndrome, polycythaemia, hypocalcaemia, and hyperbilirubinaemia. ${ }^{58}$ Attempts to normalise blood glucose concentrations in pregnant patients became the cornerstone of treatment. Intensification of both glucose monitoring and insulin administration resulted in ever improving perinatal outcome. ${ }^{34}$ We used intensive blood glucose monitoring to evaluate which of two insulin dose regimens would provide better overall outcome in pregnant diabetic patients. We found a significant reduction in the rate of hypoglycaemia and hyperbilirubinaemia in neonates born to women that received the four times daily compared with the twice daily regimen. Hypoglycaemia and hyperbilirubinaemia are the two most frequent complications expected in infants of diabetic mothers. The reduction in the rate of both hypoglycaemia and hyperbilirubinaemia probably results from the significant improvement in variables of glycaemic control, in turn resulting from the increase in the mean dose of

Table 2 Variables of glycaemic control and obstetric data of diabetic pregnant women. Values are means (SD) unless stated otherwise

\begin{tabular}{|c|c|c|c|c|c|c|}
\hline \multirow[b]{2}{*}{ Variable } & \multicolumn{3}{|c|}{ Gestational diabetes } & \multicolumn{3}{|c|}{ Pregestational diabetes } \\
\hline & $\begin{array}{l}\text { Insulin twice } \\
\text { daily }\end{array}$ & $\begin{array}{l}\text { Insulin four } \\
\text { times daily }\end{array}$ & $\begin{array}{l}\text { Difference } \\
(95 \% \mathrm{CI})\end{array}$ & $\begin{array}{l}\text { Insulin twice } \\
\text { daily }\end{array}$ & $\begin{array}{l}\text { Insulin four } \\
\text { times daily }\end{array}$ & $\begin{array}{l}\text { Difference } \\
(95 \% \mathrm{CI})\end{array}$ \\
\hline No of women & 136 & 138 & & 60 & 58 & \\
\hline Gestational week at delivery & $38.6(1.9)$ & $38.9(1.6)$ & $0.3(-0.1$ to 0.7$)$ & $38.3(2.0)$ & $38.1(2.8)$ & $-0.2(-1.0$ to 0.6$)$ \\
\hline Maternal weight gain $(\mathrm{kg})$ & $11.4(3.5)$ & $10.7(3.6)$ & $-0.7(-1.5$ to 0.1$)$ & $12.5(4.0)$ & $12.0(4.5)$ & $-0.5(-2.0$ to 1.0$)$ \\
\hline Capillary whole blood glucose (mmol/l) & $5.60(0.48)$ & $5.42(0.54)$ & $0.19(0.13$ to 0.25$)$ & $5.9(0.92)$ & $5.47(0.78)$ & $0.45(0.28$ to 0.60$)$ \\
\hline Haemoglobin $\mathrm{A}_{1 \mathrm{c}}(\%)$ & $5.8(1.0)$ & $5.5(1.0)$ & $-0.3(-0.2$ to -0.4$)$ & $6.7(1.8)$ & $6.2(1.3)$ & $-0.5(-0.2$ to -0.8$)$ \\
\hline Fructosamine $(\mu \mathrm{mol} / \mathrm{l})$ & $229(43)$ & $188(27)$ & $-41(-37$ to -45$))$ & $261(62)$ & $210(33)$ & $-51(-45$ to -57$)$ \\
\hline Daily insulin at delivery (units/day) & $43(84)$ & $65(80)$ & 22 (12 to 32$)$ & $92(54)$ & $120(84)$ & $28(15$ to 41$)$ \\
\hline No (\%) with adequate glycaemic control ${ }^{*}$ & $101(74)$ & $126(91)$ & 17 (8 to 26$)$ & $33(55)$ & $50(86)$ & 31 (15 to 47 ) \\
\hline $\begin{array}{l}\text { No }(\%) \text { with severe maternal } \\
\text { hypoglycaemiat }\end{array}$ & $1(0.7)$ & $1(0.7)$ & 0 & $11(18)$ & $10(17)$ & $-1(-15$ to 13$)$ \\
\hline No (\%) who had caesarean sections & $38(28)$ & $39(28)$ & 0 & $19(32)$ & $13(22)$ & $-10(-25$ to 5$)$ \\
\hline $\begin{array}{l}\text { No (\%) with pregnancy induced } \\
\text { hypertension }\end{array}$ & $12(9)$ & $11(8)$ & -1 (-11 to 9$)$ & $6(10)$ & $5(9)$ & $-1(-11$ to 9$)$ \\
\hline
\end{tabular}

${ }^{\star}$ Mean capillary blood glucose concentration $<5.8 \mathrm{mmol} / \mathrm{l}$.

†Requiring help from another person. 
Table 3 Perinatal and neonatal outcome in diabetic pregnant women. Values are numbers (percentages) unless stated otherwise

\begin{tabular}{|c|c|c|c|c|}
\hline \multirow[b]{2}{*}{ Variable } & \multicolumn{2}{|c|}{ Gestational diabetes } & \multicolumn{2}{|c|}{ Pregestational diabetes } \\
\hline & $\begin{array}{l}\text { Insulin twice } \\
\text { daily }\end{array}$ & $\begin{array}{l}\text { Insulin four } \\
\text { times daily }\end{array}$ & $\begin{array}{l}\text { Insulin twice } \\
\text { daily }\end{array}$ & $\begin{array}{l}\text { Insulin four } \\
\text { times daily }\end{array}$ \\
\hline No of women & 136 & 138 & 60 & 58 \\
\hline Mean (SD) birth weight $(\mathrm{g})$ & $3436(672)$ & $3437(587)$ & 3376 (639) & $3229(758)$ \\
\hline Perinatal mortality & $1(0.7)$ & 0 & $2(3.3)$ & $2(3.4)$ \\
\hline Major congenital anomalies $\dagger$ & $2(1.5)$ & $1(0.7)$ & $3(5.0)$ & $3(5.1)$ \\
\hline $\begin{array}{l}\text { Small for gestational age } \\
(\leqslant 10 \text { centile }) \ddagger\end{array}$ & $7(5.0)$ & $4(3.0)$ & $3(5.0)$ & $3(5.1)$ \\
\hline $\begin{array}{l}\text { Large for gestational age } \\
\qquad(\geqslant 90 \text { centile }) \ddagger\end{array}$ & $41(30)$ & $36(26)$ & $17(28)$ & $14(24)$ \\
\hline Macrosomia $(\geqslant 4000 \mathrm{~g})$ & $26(19)$ & $22(16)$ & $8(18)$ & $5(9)$ \\
\hline Apgar score $<7$ at 5 minutes & $2(1.5)$ & $6(4.3)$ & $5(8)$ & $5(9)$ \\
\hline Hyaline membrane disease & 0 & $1(0.7)$ & $4(6.7)$ & $1(1.2)$ \\
\hline Hypoglycaemia§ & $8(5.9)$ & $1(0.7)^{\star}$ & $12(20.0)$ & $2(3.4)^{* *}$ \\
\hline Hypocalcaemia & 0 & $1(0.7)$ & $5(8.3)$ & $6(10.3)$ \\
\hline Polycythaemiat† & $3(2.2)$ & $7(5.1)$ & $5(8.3)$ & $3(5.2)$ \\
\hline Hyperbilirubinaemiałł & $29(21)$ & $15(11)^{*}$ & $28(47)$ & $27(47)$ \\
\hline Birth trauma§§ & $3(2.2)$ & $2(1.4)$ & $1(1.7)$ & $1(1.7)$ \\
\hline Overall neonatal morbidity & $40(29)$ & $24(17)^{*}$ & $36(60)$ & $29(50)$ \\
\hline
\end{tabular}

* $\mathrm{P}=0.02 ;{ }^{*} \mathrm{P}=0.01$.

†Fatal, requiring surgery, or having significant psychological effects on fetus in later life. $\ddagger$ According to Brenner et al. ${ }^{16}$

§Plasma glucose concentration $<1.9 \mathrm{mmol} / \mathrm{l}$ in term infants or $<1.4 \mathrm{mmol} / \mathrm{l}$ in preterm infants at least on two different occasions during first 48 hours of life.

ISerum calcium concentration $<2.0 \mathrm{mmol} / \mathrm{l}$.

††Venous haematocrit $>65 \%$.

¥¥Serum bilirubin concentration $>205 \mathrm{mmol} / \mathrm{l}$ at $\geqslant 34$ weeks' gestation or $>137 \mathrm{mmol} / \mathrm{l}$ at $<34$ weeks' gestation.

$\S \S$ Peripheral nerve injury or bone fracture.

insulin. Hypoglycaemia and hyperbilirubinaemia are not only good surrogate outcome measures but also serve as indications for treatment (glucose infusion and phototherapy respectively). ${ }^{18}$

\section{Rate of macrosomia}

The four times daily dose regimen did not cause further reduction in the incidence of macrosomic infants, as was observed by De Veciana et al..$^{9}$ This may indicate that the twice daily dose regimen has already brought the incidence of macrosomic infants to the possible minimum. The remaining cases may thus be attributable to other factors such as maternal age, parity, maternal weight, and weight gain during pregnancy, as well as constitutional factors. ${ }^{19-22}$ None the less it is possible that a reduction in microsomic infants and some other less frequent complications may have been shown by studying the groups further. Such a difference clinically would, however, be immaterial.

\section{Long term and other effects}

In short term studies such as ours improvement of long term results is not approached. However, any

\section{Key messages}

- Improving maternal glycaemic control during pregnancy is the key to better perinatal outcome

- In pregnant diabetic women insulin four times daily achieved better glycaemic control and lower rate of perinatal complications (hypoglycaemia, hyperbilirubinaemia) than insulin twice daily

- Better glycaemic control resulted from a larger total daily insulin dose

- The intensified regimen did not lead to higher rate of severe maternal hypoglycaemia further improvements in glycaemic control during pregnancy may be expected to prevent fetal hyperinsulinism and to reduce even its long term effects, such as later life obesity and diabetes in the offspring. ${ }^{23-25}$

All the improvements we recorded should be seen in the context that there were no more cases of maternal hypoglycaemic events. In contrast, the diabetes control and complications trial study found that improvement of glycaemic control in non-pregnant women was associated with increased frequency of hypoglycaemic events. ${ }^{10}$ Thus, in our study the net effect of the four times daily regimen compared with the conventional twice daily dose regimen may be judged as advantageous, without increasing the risk to mother and fetus.

\section{Practical aspects}

Our results show that a dose regimen that is neither more complicated nor more expensive than the conventional twice daily regimen provides a better outcome. Although the four times daily regimen involves two more injections a day than the twice daily regimen pure insulin can be given. The twice daily regimen entails frequent changes in the ratio of the constituents of each injection, whereas the four times daily dose regimen entails injections of only one type of insulin. Insulin may be given by "pens," which are more convenient for patients and medical staff and which provide accurate doses of drug. ${ }^{26}$ Additionally, patients may have meals at more flexible intervals and may adjust the dose of insulin to variables such as exercise and appetite, whereas intermediate insulin dictates the timing and size of meals.

HaEmek Medical Center's department of obstetrics and gynaecology is affiliated with the Rappaport Faculty of Medicine, Technion-Israel Institute of Technology, Haifa, Israel.

Contributors: ES and ZN conceived jointly the basic idea for the study. ZN was the principal clinician who executed the protocol. EW delineated the study group size, provided the randomisation, and performed the statistical analysis. IB-S and ZN wrote the paper. All authors participated in approval of the detailed study design and participated in periodical follow up of its advancement, and each will act as a guarantor for the paper. Funding: None.

Competing interests: None declared.

1 Drexel H, Bichler A, Sailer S, Breier C, Lisch HJ, Braunsteiner H, et al. Prevention of perinatal morbidity by tight metabolic control in gestational diabetes mellitus. Diabetes Care 1988;11:761-8.

2 Langer O, Mazze R. The relationship between large-for-gestational-age infants and glycemic control in women with gestational diabetes. Am J Obstet Gynecol 1988:159:1478-83.

3 Jovanovic L, Druzin M, Peterson CM. Effect of euglycemia on the outcome of pregnancy in insulin-dependent diabetic women as compared with normal control subjects. Am J Med 1981;71:921-7.

4 Langer O, Rodriguez DA, Xenakis EMJ, McFarland MB, Berkus MD, Arredondo F. Intensified versus conventional management of gestational diabetes. Am J Obstet Gynecol 1994;170:1036-47.

5 American College of Obstetrics and Gynecology. Diabetes and pregnancy. Technical bulletin No 200. Washington, DC: ACOG. Dec, 1994.

6 National Diabetes Data Group. Classification and diagnosis of diabetes mellitus and other categories of glucose intolerance. Diabetes 1979;28:1039-57.

7 Carpenter MW, Coustan DR. Criteria for screening tests of gestational diabetes. Am J Obstet Gynecol 1982;144:768-73.

8 American Diabetes Association. Medical management of pregnancy complicated by diabetes, 2nd ed. In: Jovanovic-Peterson L, ed. Alexandria, VA: ADA, 1995

9 De Vaciana M, Major CA, Morgan MA, Asrat T, Toohey JS, Lien JM, et al. Postprandial versus preprandial blood glucose monitoring in women with gestational diabetes mellitus requiring insulin therapy. $N$ Engl J Med 1995;333:1237-41.

10 The Diabetes Control and Complications Trial Research Group. The effect of intensive treatment of diabetes on the development and progression of long-term complications in insulin-dependent diabetes mellitus. N Engl J Med 1993:329:977-86. 
11 Vaughan NJA, Oakley NW. Treatment of diabetes in pregnancy. Clin Obstet Gynecol 1986;13:291-306.

12 Hagay ZJ, Reece EA. Diabetes mellitus in pregnancy. In: Reece EA Hobbins JC, Mahoney MJ, Petrie RH, eds. Medicine of the fetus and mother. Philadelphia: Lippincott, 1992.

13 Weiss PAM, Hofmann H. Intensified conventional insulin therapy for the pregnant diabetic patient. Obstet Gynecol 1984;64:629-37.

14 The Diabetes Control and Complications Trial Research Group. Pregnancy outcomes in the diabetes control and complications trial. Am J Obstet Gynecol 1996;174:1343-53.

15 Hare JW, White P. Gestational diabetes and the White classification Diabetes Care 1980;3:394.

16 Brenner WE, Edelman DA, Hendricks CH. A standard of fetal growth for the United States of America. Am J Obstet Gynecol 1976;126:555-64

17 Pedersen J. The pregnant diabetic and her newborn. Baltimore, MD: Williams and Wilkins, 1967.

18 Mountain KR. The infant of the diabetic mother. Baillière's Clin Obstet Gynecol 1991;5:413-42.

19 Spellcy WN, Miller S, Winegar A, Peterson PQ. Macrosomia-maternal characteristics and infant complications. Obstet Gynecol 1985;66:158-61.

20 Jarrett RJ. Reflection on gestational diabetes mellitus. Lancet 1981;2:1220-1.
21 Green JR, Schumacher LB, Pawson IG, Partridge JC, Krechmenr N. Influence of maternal body habitus and glucose tolerance on birthweight Obstet Gynecol 1991;78:235-40.

22 Leonardi MR, Bottoms SF. Increased incidence of large for gestational age infants not attributable to gestational diabetes. Am J Obstet Gynecol 1996;174:393.

23 Martin AO, Simpson JL, Ober C, Frenkel N. Frequency of diabetes mellitus in mothers of probands with gestational diabetes: possible maternal influence on the predisposition to gestational diabetes. Am J Obstet Gymecol 1985; 151:471-5.

24 Pettitt DJ, Aleck KA, Baird HR, Carraher MJ, Bennett PH, Knowler WC. Congenital susceptibility to NIDDM. Role of intrauterine environment. Diabetes 1988:37:622-8.

25 Dörner J, Steindel E, Tholke H, Sehliak V. Evidence for decreasing prevalence of diabetes mellitus in childhood apparently produced by prevention of hyperinsulinism in the foetus and newborn. Exp Clin Endocrino $1984 ; 84: 134-42$

26 Dunbar JM, Madden PM, Gleeson DT, Fiad TM, McKenna TJ. Premixed insulin preparations in pen syringes maintain glycemic control and are preferred by patients. Diabetes Care 1994;17:874-8.

(Accepted 16 August 1999)

\title{
Vertical transmission rates for HIV in the British Isles: estimates based on surveillance data
}

\author{
Trinh Duong, A E Ades, Diana M Gibb, Pat A Tookey, Janet Masters
}

\begin{abstract}
Objective To estimate and interpret time trends in vertical transmission rates for HIV using data from national obstetric and paediatric surveillance registers. Design Prospective study of HIV infected women reported through obstetric surveillance. HIV infection status of the child and onset of AIDS were reported through paediatric surveillance. Rates of vertical transmission and progression to AIDS rate were estimated by methods that take account of incomplete follow up of children with indeterminate infection status and delay in AIDS reporting.

Setting British Isles.

Subjects Pregnant women infected with HIV whose infection was diagnosed before delivery, and their babies.
\end{abstract}

Main outcome measures Mother to child transmission of infection and progression to AIDS in children.

Results By January 1999, 800 children born to diagnosed HIV infected women who had not breast fed had been reported. Vertical transmission rates rose to $19.6 \%(95 \%$ confidence interval $8.0 \%$ to $32.5 \%)$ in 1993 before falling to $2.2 \%(0 \%$ to $7.8 \%)$ in 1998. Between 1995 and 1998 use of antiretroviral treatment increased significantly each year, reaching $97 \%$ of live births in 1998 . The rate of elective caesarean section remained constant, at around 40\%, up to 1997 but increased to $62 \%$ in 1998 . Caesarean section and antiretroviral treatment together were estimated to reduce risk of transmission from $31.6 \%$ ( $13.6 \%$ to $52.2 \%)$ to $4.2 \%$ ( $0.8 \%$ to $8.5 \%)$. The proportion of infected children developing AIDS in the first 6 months fell from $17.7 \%$ (6.8\% to 30.8\%) before 1994 to $7.2 \%$ ( $0 \%$ to $15.7 \%$ ) after, coinciding with increased use of prophylaxis against Pneumocystis carinii pneumonia.

Conclusions In the British Isles both HIV related morbidity and vertical transmission are being reduced through increased use of interventions.

\section{Introduction}

Randomised controlled trials have established that zidovudine can significantly reduce the risk of vertical transmission of HIV. ${ }^{1}$ The protective effect of elective caesarean section has been confirmed by a recent meta-analysis of cohort studies ${ }^{2}$ and a randomised controlled trial. ${ }^{3}$ The combined effect of these interventions is reported to reduce transmission to $2 \%$ or less in some cohort studies. ${ }^{24}$

However, the general population of infected women may differ from those recruited into trials or cohort studies in terms of adherence to antiretroviral treatment, previous exposure to antiretroviral treatment, and uptake of elective caesarean section. It is therefore essential to monitor uptake of interventions and vertical transmission rates in the wider population. Here we present estimates of HIV vertical transmission rates in the British Isles. ${ }^{5}$

\section{Methods}

\section{Population studied}

Since 1989 pregnant women in the British Isles known to be infected with HIV have been notified to the Royal College of Obstetricians and Gynaecologists. Obstetricians are asked to report on outcome of pregnancy and, since 1995, on mode of delivery and uptake of antiretroviral treatment. After initial notification of children born to infected mothers to the British paediatric surveillance unit, paediatricians are asked for diagnostic and clinical data. Subsequently, children of indeterminate infection status are followed until infection status is known. ${ }^{5}$ All reporting is voluntary and confidential. This analysis is confined to prospectively ascertained children whose mothers' HIV infection was reported to have been diagnosed before delivery.

\section{Statistical methods}

Statistical methods to avoid biased estimation of vertical transmission rates due to incomplete follow up of
Editorial by Nicoll

Department of Epidemiology and Public Health, Institute of Child Health, London WC1N 1EH

Trinh Duong statistician A E Ades reader

Pat A Tookey senior research fellow Janet Masters research assistant

Clinical Trials Unit, Medical Research Council, Mortimer Market Centre,

London

WC1E 6AU

Diana M Gibb senior lecturer in epidemiology

Correspondence to: A E Ades a.ades@ich. ucl.ac.uk

BMJ 1999;319:1227-9

website extra

A longer version of this paper is available on the BMJ's website

www.bmj.com 